\title{
Design studio practice in the context of architectural education: a narrative literature review
}

\author{
Upeksha Hettithanthri ${ }^{1,2}$ (D) Preben Hansen ${ }^{1}$ (D)
}

Accepted: 10 August 2021 / Published online: 23 August 2021

(c) The Author(s) 2021

\begin{abstract}
This review aims to synthesize the current knowledge on the conventional design studio context. This is a narrative literature review based on articles published within the last ten years, while 60 articles were selected for the literature review following a rigorous filtration process. The final articles were selected by applying inclusion and exclusion criteria to the initially selected articles. This review has synthesized the current knowledge on design studio contexts and will review the conventional design studio context, design studio practices that take place within design studios and use of digital tools. The main aim of this study is to broaden the understanding of design studio contexts and to comprehend the types of design studio contexts available in architectural studies. Furthermore, it discusses the digital tools used in design studio practices in the last 10 years. A thematic analysis was conducted in reviewing the articles. It is to be noted that no research has been carried out except one on generating design studio context outside the conventional design studio set-up. This study aims to identify the potential research possibilities of context generated design studios to engage in design studies.
\end{abstract}

Keywords Design studio context $\cdot$ Conventional design studio $\cdot$ Design process $\cdot$ Studio practices

\section{Introduction}

The meaning of the word context differs according to the situation (Koffeman \& Snoek, 2019). As explicated by Edwards and Miller (2007, p. 265), the meaning of the context in an educational set-up is a bounded container that allows various activities to occur. Further, the context has a fluid nature that could accommodate the flexibility to entertain a

Upeksha Hettithanthri

dilini@dsv.su.se

Preben Hansen

preben@dsv.su.se

1 Department of Computer and Systems Sciences/DSV, Stockholm University, Postbox 7003, 16407 Kista, Sweden

2 National School of Business Management, Green University Town, Pitipana, Homagama, Sri Lanka 
set of practices (Koffeman \& Snoek, 2019). The design studio context is creating a learning environment that mainly focuses on increasing the creative learning abilities of the students (Ibrahim \& Utaberta, 2012). The architectural design studio context is similar to other design studio contexts in graphics, fashion and communication disciplines, and it is almost similar in physical infrastructure and human involvement (Corazzoa, 2019). The sole difference lies in the specific tasks executed within the architectural design studio context. Students engage in solving architectural and spatial problems in architectural design studios. The physical infrastructure of the architectural design studio can even be used by other design disciplines because there is not much of a difference in the physical environment of the design studio. As illustrated by Emam et al. (2019, p. 164), design studios mainly cater to design education where students engage in project-based learning. The design studio context consists of situational and contextual factors, in addition to the engagement of students and lecturers. Orbey and Sarioglu (2020) claimed that the activities that occur within the design studio context had empowered the creative design abilities of students. The physical environment of the design studio will never create a studio context without the collaborative engagement of the students and lecturers (Rodriguez et al., 2018). As depicted by Bashier (2014, p. 426), the context of the design studio can be identified as a collaborative learning environment where students and lecturers are engaged in learning and teaching through real-life problem scenarios. According to Grover et al. (2020, p. 2), the design studio context motivates the intrinsic creativity of students through the learning environment.

\section{Conventional design studio (CDS)}

The conventional design studio context is a learning environment located within an institutional set-up with all the infrastructure created to collaborate, brainstorm, learn by doing, and engage in reflective practice (Orbey \& Sarığlu Erdoğdu, 2020). CDS context is a creative learning space where students gather with peers and tutors to solve design problems. Further, CDS is identified as a physical container created for the social interaction of students and design tutors (Corazzoa, 2019). The physical boundaries of the conventional design studio are limited to an academic or an institutional environment (Kay Brocato, 2009). However, pedagogical practices have heavily contributed to making the design studio conventional. Existing studies on CDS articulate it as an engagement or an approach for teaching occurring within a specific environment. Schon (1987, pp. 41-43) defines the design studio through four central learning concepts. He explained the design studio as (1) a culture where students and lecturers work together, (2) as a physical fixed space where teaching and learning can occur, (3) studio as a way of teaching and learning, and (4) as a program of activity. The learning culture of the design studio is students and lecturers working together, sharing ideas, testing best solutions, displaying the results, and this creates an interactive knowledge sharing, practice-based learning culture where students learn through reflection in action. This pedagogical practice is a unique learning culture. However, this reflective practice and collaborative learning culture is not limited only to CDS. This practice can even be seen in non-conventional, virtual, blended or online design studios. Echoing this fact, Schon (1987, p. 44) highlights "the studio as a physical fixed space where teaching and learning can be happening". In strengthening the definition given by Schon, Corazzoa (2019, p. 1255) has defined the design studio context through six elements. They are (1) studio as making, (2) studio as bridging, (3) studio as meaning, (4) studio as enabling, (5) studio as backgrounding and (6) studio as disciplining. The Design 
studio context enables students to work with materials and make artefacts. This fact further strengthens the point of learning by doing. Creating artefacts can happen in a CDS setting or even in a virtual/blended platform where students could collaborate online. In non-conventional virtual design studios, making happens through a digital medium by incorporating digital tools and technologies such as Auto Cad, 3D max, etc. These six elements are not only seen in non-conventional virtual/blended and online design studios; they are also visible in CDS. This Literature Review focuses on identifying the types of design studio contexts, including studio practices.

In defining the Conventional Design Studio, it is stated that as a comprehensive model of design learning established many decades before, its system, built structure, and epistemology intermingle together to create a unique learning environment following problembased learning (Brandt et al., 2013). Design studio context provides room for both implicit and explicit learning (Park, 2020). We identified the conventional design studio as a structured, systematic learning and designing process by being in a dedicated fixed built structure. However, students in the conventional design studio face many problems, making the process adopted in the CDS more problematic (Chen, 2016). In the context of CDS, the design process that is followed is more linear; the instructors set the design process into small tasks and request students to work according to those instructions (Chen, 2016). Students in the CDS are guided by expert designers in the industry (Rodriguez et al., 2018). The conventional design studio has reported that students have less motivation and engagement, and there are many reasons behind it (Rodriguez et al., 2018). The structured, systematic process of the CDS provides a less diversified learning experience to the students, impacting their creativity and design thinking in various ways (Rodriguez et al., 2018). Moreover, the CDS context has reported the disconnection from real-world problem scenarios, highlighting that finding solutions for problems set in the outside world while sitting in a dedicated working environment might be the key reason for this disconnection (Rodriguez et al., 2018).

It is essential to understand what distinguishes the conventional design studio context from other contexts. CDS is a creative learning environment where students are assigned to solve real-life problems through creative design solutions while being in a dedicated room for designing in an institutional set-up. Furthermore, CDS is a controlled creative learning environment that has been specifically designed to engage in creative activities. However, the unique feature of the CDS is that it is accompanied by all the tools that are especially required for design. This fact distinguishes the CDS unique form from other contexts. When creating a design studio context outside of an institutional set-up, facilitating those design tools is challenging because those were designed to work within a CDS context.

\section{Design studio practices}

The studio practices are the activities students and facilitators are engaged in. The design studio context facilitates numerous activities. Students are learning by creative pursuits. They work together with their peer to find design solutions to real-life problems. Face-toface learning, peer support, assessments, and reflective practice are commonly discussed studio practices in literature. As explained by Emam et al., (2019, pp. 164-165), within the conventional design studio context, students engage in a single open-ended, projectbased problem, allowing students to solve the problem in their own way. The design solutions are generated through an iterative process, and the design solutions are continuously reviewed, judged and open for comments by the jury and the peer (Ardington \& Drury, 
2017). Another practice that is generated through students' engagements with projects is Interaction and engagement. The design studio context fosters motivation and helps to develop strong learning communities. This enhances deep learning and sustainable retention of the learning outcomes of design studies. Thus, this literature review highlights the existing evidence on commonly used studio practices.

\section{Use of tools}

Usage of tools plays a vital role in the design studio context. Students use tools for various tasks. They need the aid of tools from the beginning of the design process to the end. Some tools are supportive in creative designing, and some tools are supportive in creative design communication, whilst another set of tools are supportive in teaching and learning in design studios. Tools used in design studios are found in both digital and manual formats. Therefore, identifying the types of tools used in design studios is one of the aims of this literature review.

This review aims to understand the design studio contexts found in literature and identify the key characteristics of the studio context. Furthermore, this review explores the type of studio practices found within the design studio context. This review will give a broad understanding of the design studio context and existing studio practices. This study has adopted the narrative literature review methodology, and articles published over the last decade (2010-2020) were selected. The reason for the selection is that the writer needed to explore how teaching and learning have taken place in the recent past and how it has changed from its original form. The literature has revealed a cross-section of how the CDS and its practices have been explored and investigated by other researchers throughout the last decade.

To summarize, the CDS has shown problems in the areas of (1) student engagement, (2) motivation, (3) disconnection from real-world problem scenarios. These issues demand a move from the CDS context. Moreover, there is a substantial gap in literature on context generated design studios that could create the design studio outside the conventional framework.

\section{Problem formulation}

The context of education has changed rapidly from face-to-face learning to online distance learning. In addition, the use of digital tools for teaching and learning has escalated drastically. How these changes have reflected on architectural studio context is a subject that lacks discussion and, therefore, an important aspect that warrants further research.

The conventional design studio context has not undergone many changes from its original form. The contextual influences on students' design process are important; however, it has lacked in-depth research over the last few decades. The aim of this literature review is to understand how those researchers have been identified within the design studio context in the respective empirical studies and to assess the contextual contribution towards design studio practices. For this purpose, empirical studies on the design studio context and design studio practices were selected after a rigorous filtration process.

Research has indicated that the learning needs of contemporary architectural learners have evolved to a complex level. Therefore, it becomes imperative to explore the potential practices that could be adopted by using digital technologies to benefit future architectural 
learners. The studio has been recognized as the unique learning context for architectural studies. However, stepping out from the typical pedagogic framework while keeping unique elementary needs of the conventional design studio context is an important fact that many researchers have not explored. The problem has been formulated to understand the contextual contribution of the design studio to the design studio practices and to understand how the digital technologies could be used in teaching and learning in design studios.

\section{Research questions}

This literature review was conducted to find answers for the following research questions:

RQ 1-What are the architectural design studio contexts available?

RQ 2-What are the architectural design studio practices available?

RQ 3-What are the digital tools and technologies used in architectural design studios?

\section{Methodology}

For this literature review, the narrative review methodology was adopted (SAGE Internet Research Methods, 2019). Narrative literature reviews consist of a credible, comprehensive, in-depth analysis of a particular subject domain, allowing the writer to critically analyze and summarize theories and concepts (Baker, 2016) (Green et al., 2006). Adopting a narrative literature review methodology will be supportive in identifying patterns and trends in the literature and identify existing gaps in the body of the knowledge domain (Green et al., 2006). The study needed to generate more focus on the research questions and discover and produce comprehensive, methodological, and logical answers based on the publications selected. A narrative literature review provides a theoretical focus on the existing knowledge domains and logical explanations of available knowledge sources. Even though we have adopted the narrative literature review methodology, a rigorous systematic method of searching and selection of articles adopted is further explained in "Search strategy" section.

The study adopted literature within the last ten years because finding the most current studio practices and design processes within the design studio context is important in framing the research. The primary selection criteria for the articles focused on identifying papers containing data and empirical studies on the architectural design studio context, which explains the design process of the students. Furthermore, the necessary keywords for advanced study were established based on the above focus.

\section{Search strategy}

For this study, articles were browsed from the following databases: Scopus, Web of Science, and Science Direct. The reason behind selecting these three databases is that they are widely used for literature reviews on architectural studies by many scholars, and they contain a heavy number of articles related to architectural studies. At the initial search, 1594 peer-reviewed articles were found. For this search, articles published from 2010-2020 were selected as the time duration. This specific choice of publication years was to meet the study's requirement of exploring recent knowledge domains and contemporary practices related to design studios. 
Articles were browsed using several keywords, and those keywords were generated by using similar meanings and applications of the design studio. The appearance of those keywords in all sections, including the title, abstract, and full text, were taken into account. "Architectural Design Studio" OR "Design Studio Education" OR "Design studio context" OR "Context of Design studio" OR "Design Studio environment" OR "Design studios" OR "Learning in Architectural Design Studios" OR "Interior Design Studios" AND "Online Design Studios" OR "Mobile Design Studios” OR "Remote Design Studios" OR "Distance Learning in Architectural Studio" were used as keywords in browsing. Articles were selected irrespective of region or country. Journal and conference articles have both been taken into account for the review.

\section{Inclusion and exclusion}

The initial screening included reading the abstracts of the selected article and thereafter selected 663 relevant articles for further examination. Duplicates were removed, after which 416 articles remained. Design studio experiments conducted in order for IT students to discover HCI matters were removed at the second filtration due to the lack of explanations on design studio context. Broadcasting design studios and studio-based learning in computer science and linguistic studies were also excluded. Since the design studio context is almost equivalent to the architectural design studio, literature on graphic design studios and product design studios were included in this study. Landscape design studios that have conducted empirical research on fieldwork with no involvement of digital technology or digital tools were excluded at the second filtration. Empirical studies on design studio practices, empirical studies on conventional design studios, studio space and context, empirical studies on the use of digital and manual tools in design studio education, virtual design studios, blended learning design studios and teaching experiments in design studios were included for the full article review. In addition, literature reviews conducted on architectural design studios were included for the review because those contained summaries of the knowledge gained through referring to many research studies found on architectural design studio contexts. This literature review aims to understand how the CDS context and its practices have been explained in the existing literature. Concept papers found did not encompass sufficient information in explaining the design studio context, the role of the studio and studio practices. Therefore, those papers were excluded. Empirical studies on creative design studio practices were included; however, studies on creativity and creative cognition were excluded because creativity is a different domain and exploring creativity is not a central aim of this study. Articles that lacked explanation on design studio practices, workshop summaries, and articles with limited access to the full text were excluded at the third filtration. Moreover, for the review, quantitative, qualitative, mixed-method, and ethnographic studies were selected (Fig. 1).

\section{Eligibility criteria for inclusion}

After the rigorous filtration process, 60 peer-reviewed articles written in the English Language were selected for the literature review. The following eligibility criteria were established to find the current status of literature in the architectural design studio context. Criteria were established in answering the research questions generated. In answering RQ1, Criteria 1 and 2 were created. This will support filtering the best-fit articles to describe the design studio context and broaden the understanding of the design studio context as a 


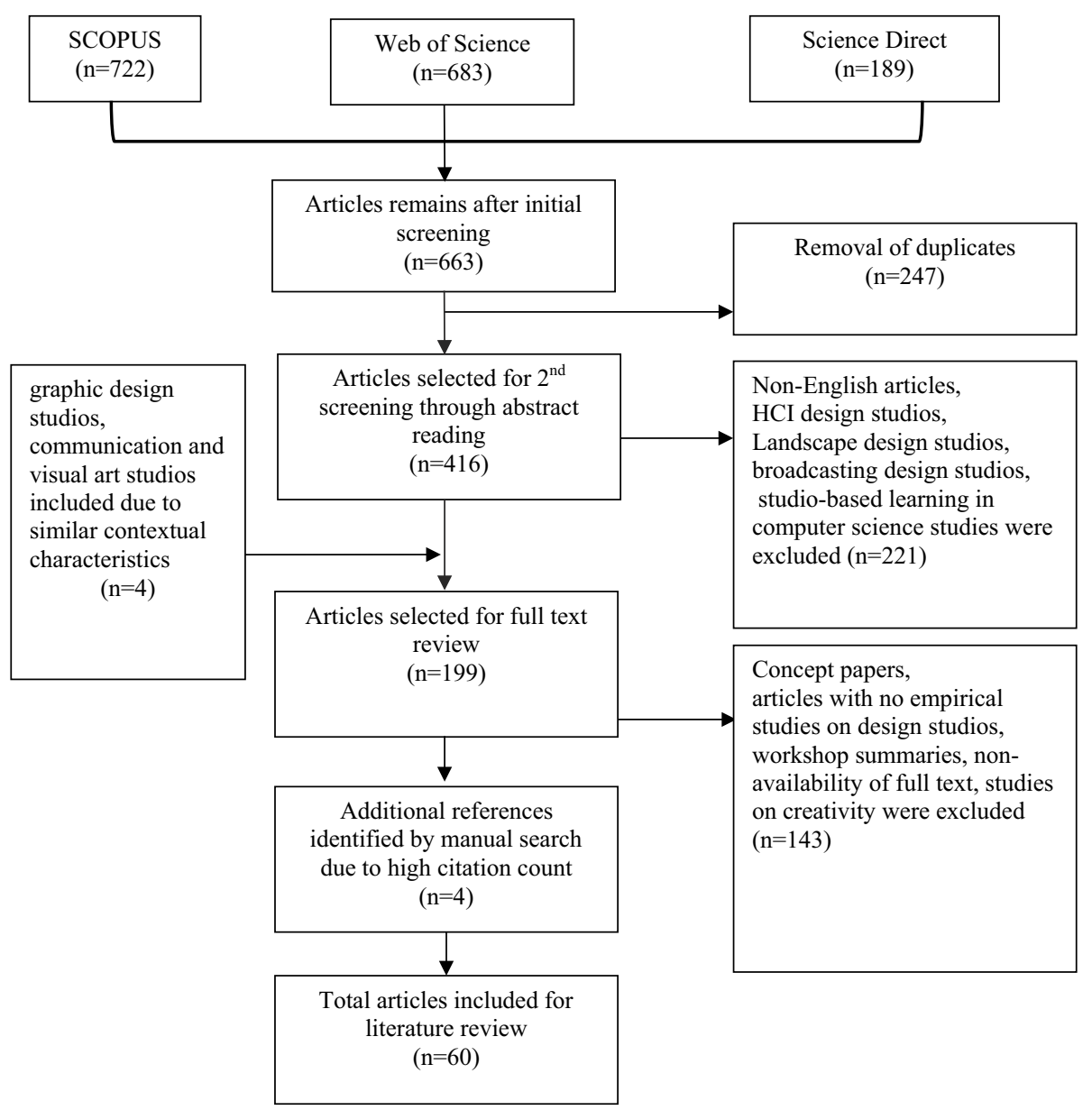

Fig. 1 Process map of article selection

learning environment. Criteria 3,4 and 5 was created in answering RQ2. RQ 2 focuses on determining the current studio practices found in literature. In investigating this matter, the studio practice has been divided into two major streams: pedagogical practices and creative design practices and studies conducted under those areas were mapped accordingly under the categories created. RQ 3 focuses on understanding the types of digital tools and technologies used in design studios, and criteria 6 and 7 address this matter.

\section{List of criteria}

Criteria 1 Empirical studies describing conventional design studio context

Criteria 2 Empirical studies on distance, virtual and blended design studio contexts.

Criteria 3 Empirical studies on creating design studio context outside the conventional institutional set-up

Criteria 4 Empirical studies on pedagogical practices in design studios 
Criteria 5 Empirical studies on creative design practices in design studios

Criteria 6 Empirical studies on digital pedagogical tools used in design studio practice

Criteria 7 Empirical studies on creative digital design tools used in design studios

\section{Results}

The table of criteria generated the following outcomes. Among 27 articles, 60 described the conventional design studio context through their empirical studies. Amid those 27 articles, 7 articles described the conventional design studio context in addition to virtual/ blended /online design studios. There was only one article amidst them, which had stepped beyond the conventional studio set-up and facilitated the students' design process in a noninstitutional environment, and it was a fieldwork project. 34 articles were discussed pedagogical practices within the design studio context. Perusing the articles, it was evident that the research interest in pedagogical practices within design studios has escalated within the last ten years. 21 studies generated discussions on creative design practices. Furthermore, 21 articles with discussions on digital pedagogical tools used in design studios were found, and 13 articles discussed creative digital design tools. As shown in Table 1, we found a substantial gap in studies focusing on context generated design studios.

\section{Methodology}

The study adopted the Thematic analysis based on the Grounded Theory under the qualitative methodology in analyzing data. Grounded theory is a mechanism that is applied in order to build a theory from available data (Corbin \& Strauss, 2020). In the application of Grounded Theory, it is unnecessary to start with a pre articulated hypothesis or a theory, but it allows the researcher to build a theory based on the data generated through empirical study (Byrne, 2016). Thematic analysis is a methodology that could show existing patterns in data. Thematic Analysis comes under the umbrella of qualitative research methodology, which could develop themes through the data gathered. The thematic analysis reveals a pattern within the recognized data that has emerged through analysis categories (Jennifer Fereday \& Eimear Muir-Cochrane, 2006). This was guided by 6 phases of thematic analysis, and an inductive approach has been undertaken (Hoskyns, 2016). Utilizing an inductive approach in qualitative data analysis is a method that involves reading raw data and generating categories and themes based on the researcher's criteria instead of adhering to existing theories. The inductive approach is a bottom-up method where the researcher uses observations to see the patterns. Moreover, the inductive approach allows the researcher to develop a theory that emerges from the data (Yukhymenko et al., 2014).

Familiarizing with the data, creating initial codes, searching for themes, reviewing themes, defining the themes, and reporting were the significant six steps to generate themes. As the initial step of the thematic analysis, important data identified through rigorous filtration were extracted from the articles. The data was fed into a codebook in an Excel sheet. The study followed a three-phased coding methodology commencing with open coding. The coding was conducted to seek the answers to the research questions generated. Firstly, the narrations were coded into multiple open codes. Open codes consist of narrations on the design studio context, virtual studios, studio practices, experiments, examples, explanations on tools, technology and multiple related facts. In order to filter the data generated from open coding, it was further clustered into meaningful axial codes by 
Table 1 Table of criteria

\begin{tabular}{|c|c|c|c|c|c|c|c|}
\hline Paper & $\mathrm{C} 1$ & $\mathrm{C} 2$ & $\mathrm{C} 3$ & $\mathrm{C} 4$ & $\mathrm{C} 5$ & C6 & C7 \\
\hline 1. Kuyrukçu and Kuyrukçu (2015) & $\times$ & & & $x$ & & & \\
\hline 2. Soliman (2017) & $x$ & & & $x$ & & & \\
\hline 3. Rodriguez et al. (2018) & $x$ & $x$ & & & $x$ & & \\
\hline 4. Emam et al. (2019) & $x$ & & & & $x$ & & \\
\hline 5. Grover et al. (2020) & $x$ & & & $x$ & & & \\
\hline 6. Marshalsey and Sclater (2018) & $\times$ & $x$ & & $x$ & $\times$ & & \\
\hline 7. Orbey and Sarıoğlu Erdoğdu (2020) & & & & $x$ & & & \\
\hline 8. Ardington and Drury (2017) & $x$ & & & $x$ & & & \\
\hline 9. Mewburn (2012) & & & & $x$ & & & \\
\hline 10. Utaberta et al. (2015) & $x$ & & & $x$ & $\times$ & & \\
\hline 11. Djabarouti and O'Flaherty (2019) & & & $x$ & $x$ & & & \\
\hline 12. Kaiser and Ogoli (2016) & & & & $x$ & & & \\
\hline 13. Gencosmanoglu et al. (2011) & $x$ & & & $x$ & & & \\
\hline 14. Pontus Wärnestål (2016) & $x$ & & & $x$ & & $x$ & \\
\hline 15. Fleischmann (2019) & $x$ & $x$ & & & & & \\
\hline 16. Crowther (2013) & $x$ & & & $x$ & & & \\
\hline 17. Vosinakis and Koutsabasis (2013) & & $x$ & & & $x$ & $x$ & \\
\hline 18. Ibrahim and Utaberta (2012) & $x$ & & & $x$ & $x$ & & \\
\hline 19. Hassanpour et al. (2015) & & & & $x$ & $x$ & & \\
\hline 20. Mewburn (2012) & $\times$ & & & $x$ & & & \\
\hline 21. Corazzoa (2019) & $x$ & & & & & & \\
\hline 22. Yurtkuran and Taneli (2013) & $x$ & & & $x$ & $\times$ & & \\
\hline 23. Ciravoğlu (2014) & & & & $x$ & & & \\
\hline 24. Ioannou (2018) & & $x$ & & & & $\times$ & $\times$ \\
\hline 25. Marta Masdéu and Josep Fuses (2017) & & $x$ & & & & $x$ & $x$ \\
\hline 26. Utaberta and Hassanpour (2012) & & & & $x$ & & & \\
\hline 27. Feier and Milincu (2015) & & & & $x$ & $x$ & & \\
\hline 28. Bashier (2014) & & & & $x$ & & & \\
\hline 29. Megahed (2018) & $x$ & & & $x$ & & & \\
\hline 30. Kara (2015) & & & & & & $\times$ & $\times$ \\
\hline 31. Ismail et al. (2012) & $\times$ & & & & & & $\times$ \\
\hline 32. Fleischmann (2018) & & $x$ & & & & $\times$ & \\
\hline 33. Yavuz and Yildirim (2012b) & & & & & & $\times$ & $\times$ \\
\hline 34. Hundhausen et al. (2011) & & $x$ & & $x$ & & $\times$ & \\
\hline 35. Wang (2010) & & & & $x$ & $x$ & & \\
\hline 36. Cho (2017) & & & & $x$ & $x$ & & \\
\hline 37. Lloyd (2013) & & $x$ & & & & $\times$ & $x$ \\
\hline 38. Park et al. (2019) & $\times$ & & & & $\times$ & & \\
\hline 39. Wragg (2019) & & $x$ & & & $x$ & & $x$ \\
\hline 40. Kalantar and Borhani (2016) & & & & $x$ & $\times$ & & \\
\hline 41. Yavuz and Yildirim (2012a) & & & & & & $x$ & $\times$ \\
\hline 42. Katherine Cennamo and Carol Brandt (2012) & $x$ & & & $x$ & & & \\
\hline 43. Pektas (2012) & $x$ & $x$ & & & & $\times$ & \\
\hline 44. Pektaş (2015) & & $x$ & & & & $x$ & $x$ \\
\hline
\end{tabular}


Table 1 (continued)

\begin{tabular}{|c|c|c|c|c|c|c|c|}
\hline Paper & $\mathrm{C} 1$ & $\mathrm{C} 2$ & $\mathrm{C} 3$ & $\mathrm{C} 4$ & C5 & C6 & C7 \\
\hline 45. Bâldea et al. (2015) & & $x$ & & & & $x$ & \\
\hline 46. Ham and Schnabel $(2011$, p. 0) & & $x$ & & & & $x$ & \\
\hline 47. Nicolai and Khalid (2017) & & $x$ & & $\times$ & & $x$ & \\
\hline 48. Fraser and Don (2011) & & & & $\times$ & & $x$ & $x$ \\
\hline 49. KhakZand and Babaei (2018) & & & & $x$ & $x$ & & \\
\hline 50. Varinlioğlu et al. (2018) & & & & & & $x$ & $x$ \\
\hline 51. Safin et al. (2012) & & & & & & $x$ & $x$ \\
\hline 52. Cho et al. (2016) & $x$ & $x$ & & & $x$ & $x$ & $x$ \\
\hline 53. Cho and Cho (2014) & $x$ & $x$ & & & $x$ & & \\
\hline 54. Adiloglu (2011) & & & & & $x$ & $x$ & \\
\hline 55. Güler (2015) & & & & & $x$ & $x$ & \\
\hline 56. Saghafi et al. (2012) & $x$ & $x$ & & & & & \\
\hline 57. Vyas (2013) & & & & $x$ & $\times$ & & \\
\hline 58. Mahmoud et al. (2020) & $x$ & & & $x$ & & & \\
\hline 59. Durmus Ozturk (2020) & & & & $x$ & $\times$ & & \\
\hline 60. Schön (2016) & $x$ & & & $x$ & & & \\
\hline
\end{tabular}

collecting similar subject areas into axial coding. A set of axial codes generated selective codes, which supports generating categories. Those categories generated themes that could answer the research questions created. The coding process was done through MAXQDA 11 , and the affinity diagram was used at the beginning of the process before it was fed into the software.

\section{Thematic analysis-design studio contexts}

RQ 1 is created to identify the types of design studio contexts found in literature. In this process, we identified codes in literature describing the design studio context and its characteristics. The identified codes were clustered into 22 major categories. Six themes emerged through the categories identified, and three of them described the conventional design studio context, and the rest described the non-conventional design studio context (Table 2).

The design studio contexts depicted in the literature has generated two major dimensions as conventional design studio context and non-conventional design studio context. Identified codes generated 11 major categories, and it led to identifying three major themes as material space, pedagogical practices and creative design practices, which created the dimension: conventional design studio context. On the other hand, virtual space, pedagogical practices, and creative design practices generated the dimension non-conventional design studio context. The codes and categories have shown that the CDS context has many common features that are even visible in non-conventional design studio contexts. The studio context comprises physical infrastructure such as pinup boards, tables and chairs, which support design and drawing purposes, display panels for demonstrations, and model making areas for prototyping and testing. 
Table 2 Table of categories, themes and dimensions

\begin{tabular}{|c|c|c|}
\hline Dimension & Theme & Category \\
\hline \multirow{11}{*}{$\begin{array}{l}\text { Conventional design } \\
\text { studio context } \\
\text { (CDS) }\end{array}$} & \multirow[t]{3}{*}{ Material space } & 1. Fixed infrastructure \\
\hline & & 2. Immobile physical set-up \\
\hline & & 3. Located in a university environment \\
\hline & \multirow[t]{5}{*}{ Pedagogical practices } & 4. Face to face collaboration \\
\hline & & 5. Less remote collaboration \\
\hline & & 6. Project-based learning \\
\hline & & 7. Peer support and assessment \\
\hline & & 8. Critics, juries and desk assessments, field visits \\
\hline & \multirow[t]{3}{*}{ Creative design practices } & 9. Heavy paper works \\
\hline & & 10. Pen, pencil, sketch, verbal communication \\
\hline & & 11. Heavy paper mock-ups \\
\hline \multirow{11}{*}{$\begin{array}{l}\text { Non-conventional } \\
\text { design studio con- } \\
\text { texts (NCDS) }\end{array}$} & \multirow[t]{2}{*}{ Virtual space } & 12. Location is not fixed \\
\hline & & 13. Mediated through digital platforms \\
\hline & \multirow[t]{5}{*}{ Pedagogical practices } & 14. Blended-online and face to face \\
\hline & & 15. Digital tools for collaboration \\
\hline & & 16. Peer support and assessments \\
\hline & & 17. Critics, juries and desk assessments \\
\hline & & 18. Process-based learning \\
\hline & \multirow[t]{4}{*}{ Creative design practices } & 19. Field visits, live projects \\
\hline & & 20. Digital tools for visual communication \\
\hline & & digital tools in designing, testing and prototyping \\
\hline & & 21. Less paperwork \\
\hline
\end{tabular}

The material space of the design studio is the built environment and the working culture of a studio. In defining the material space of the CDS, Corazzoa (2019, p. 1255) has explained it through five elements. The material space of a studio empowers Making, Bridging, Meaning, Enabling, Backgrounding and Disciplining. Further, explaining this fact, the CDS context comprises a space for making and creating artifacts or models for testing design ideations. The built environment and physical infrastructure contribute heavily to this fact. The activities taking place in the CDS confer meanings and values such as periodic critics, demonstrations and conversations and dialogues on projects contributing to meaningful outcomes.

Further, the material space of a CDS enables students and tutors to collaborate more through interactive activities that support sharing knowledge and experience. The material space of CDS provides the background for all learning and teaching activities and acts as a backdrop for all the activities. Finally, the material space of CDS contributes to carving the design discipline, in addition to creating a culture of designing.

The existence of martial space will not convert the space into a design studio context. To make it a studio context, the contribution of pedagogical and creative design practices has played a vital role. The codes have shown that the conventional context of the design studio is not only made by the fixed, immobile physical infrastructure of the design studio. Even within the modern, non-traditional set-up, the CDS context has found teaching and learning practices followed by the conventional master apprenticeship model. The fixed 
physical nature of the design studio is not the only demarcation that makes it conventional. In order to deem it a conventional design studio, the pedagogical practices followed would contribute.

The theme generated as "creative design practices" comprises heavy paperwork, pen and pencil work, and verbal communication. Students in CDSs produce heavy paper prototypes and rough mock-ups (Vosinakis \& Koutsabasis, 2013). In CDS, students are encouraged to build solid skills through manual drafting, rendering and making. The dependency and encouragement to utilize manual techniques and tools are higher in CDS contexts. The mixed-use of digital and manual tools is commonly evident as a pedagogical practice in CDS. The mode of engagement is face to face in the CDS context. The face-to-face interaction enables students to see and reflect on the other peer learners' design approaches and witness pitfalls in their design solutions. Problem-based learning is heavily practiced in CDS. Students learning in CDS contexts bring the problem to the design studio to solve. This has created a disconnection from real-world problem scenarios. Stepping out from the conventional context to where the problem is generated and solving it by being in the real problem context was not evident in CDS. In this scenario, live projects can be identified as a pedagogical practice found in non-conventional design studio contexts where students work and design in real problem courses by being in those contexts.

In answering RQ1, the thematic analysis brought up two major design studio contexts found in empirical studies, namely conventional design studio and non-conventional design studio contexts. The study noted that pedagogical and creative design practices contribute heavily to making the set-up conventional or non-conventional. This literature review identified CDS as a fixed, immobile, physical environment located within an institutional set-up for design students and lecturers to engage in their design practices. Moreover, the study highlights that the CDS context has been created by adopting conventional pedagogical practices into the studio without moderating them to fit into the studio user's current knowledge and skill levels. The facts found in literature strengthened the notion that the studio practices could step beyond the conventional studio environment to the context generated design studios where students could create their design studio through engagement.

\section{Studio practices}

RQ 2 was focused on identifying studio practices followed in studio contexts. The pedagogical approaches followed in the conventional design studio is mainly followed by traditional teaching and learning methods. Students are learning through the reflection of the design tutors, and this has been explained by Schon (1987), 30 years prior to his theory on the reflective practitioner. "Reflection on action" is the established pedagogical practice in the conventional design studio. The non-conventional design studio context displays more freedom when guiding novice designers. The categories have shown that the NCDSs are rich in digital technologies. It uses digital tools, software and platforms in various levels of teaching and learning. Design communication and collaboration is done chiefly through digital platforms. Blogs, Web 2.0, and social media platforms became popular among nonCDS users (Bâldea et al., 2015). The use of digital technologies for communication is not commonly available in the CDS context. Students and design tutors gather face to face at design studios and discuss, demonstrate, present and criticize design attempts. Therefore, technology does not play a significant role in communication in the conventional design studio context. 
The CDS context is featured as a safe and ideal place for problem-based learning in literature. Furthermore, it generates the feeling of a laboratory where many experiments and testing with the involvement of many parties in an open, less formal and less hierarchical workplace environment (Ardington \& Drury, 2017). Furthermore, the conventional design studio context comprises high material character with sketches, notes, artifacts, paper mock-ups, physical models and pinup presentation facilities (Vyas, 2013). The flexible infrastructure of the studio environment supports adaptability to various scenarios (Corazzoa, 2019). Compared to the virtual/ online design studio context, the material character has been replaced through digital tools such as digital drawing platforms, virtual realities etc. The change of the material space or physical infrastructure has not sufficiently influenced the creative design practice of students because it stands as a facilitator in the conventional design studio context.

It was challenging to identify clear margins on differentiating design studio practices of CDS and NCDS. The boundaries got blurred due to the most common features visible in both contexts. It was evident in literature; NCDSs practice the same pedagogical practices; however, they use different platforms. The collaboration is mostly happening through the digitally mediated platforms in NCDS contexts. In this scenario, virtual, blended, and online design studios were counted as NCDSs, where students collaborate mainly through digitally mediated virtual environments. Literature depicts that students in NCDS contexts generate more virtual and digital prototypes than students in CDS contexts. Making digital prototypes is again visible in the CDS context. Nevertheless, in virtual and online studio contexts, students mainly get the help of software and virtual realities in developing, prototyping and testing design solutions. The availability of the material space is not a mandatory factor in NCDS contexts.

Codes and categories have emphasized that CDS is more focused on bringing design problems into the design studio and engaging in solving those within the physical boundaries of the CDS. The pedagogical practices are more centered on generating solutions for real-life problems while engaging in studio activities. This practice has created a unique working culture within the CDS. Students empathize, synthesize and generate ultimate solutions to problems generated in the world outside the design studio set-up while being in the CDS environment. This scenario has even been reflected in virtual and online design studios. In the virtual, blended or online design studio, students are more distant to the actual problem domain, and the level of collaboration and levels of empathizing and synthesizing have varied from the CDS. Being in the context where a problem has occurred or working in the context where more inspiration could be found rather than bringing them back to the studio can be identified as non-conventional studio practices, and the generated codes and categories supported this fact. Process-based learning than project-based learning is visible in non-conventional studio practices.

We believe those pedagogical practices and creative design practices heavily contribute to converting the material space of the CDS into a studio context. The material space of the design studio has no meaning without creative and pedagogical practices embedded within it. From our point of view, any context could be converted into a design studio by adopting pedagogical and creative design practices and the involvement of active collaboration of students and lecturers. The flexibility of the design studio environment is a motivational factor in moving out from the conventional design studio to context generated design studios. We strongly believe that any context could be transferred into a context generated design studio by facilitating the creative and pedagogical practices within any environment. 


\section{Digital tools}

RQ 3 aims at identifying digital tools used in design studio contexts identified in RQ1. In answering this question, the study generated seven major categories via 21 major codes identified. Those categories led to three themes that fall under three dimensions. Literature shows evidence on the escalation in digital tools in design studio practice from 2012-2020 (Table 3).

The coding was done based on the understanding of what those tools support. Twenty-six codes were generated, and they were clustered into seven major categories. It was tested and depicted in literature; some digital tools have contributed to improving the students' creative design thinking ability. Most digital tools such as the internet, virtual reality, video cameras and some 3D abstractions and construction of digital 3Ds have been supported in improving creative design abilities (Lloyd, 2013). Virtual realities have created a platform for students to see beyond what they can predict and assume to see. Further, these digital tools have more flexibility to conduct many revisions, which indirectly supports the improvement of creative thinking. Using the internet for searching, identifying the precedents, analyzing and extracting relevant knowledge to solve the problem at hand also makes the designer creative in identifying potential applications. This identification generates the first dimension, "Digital tools supported for creative design thinking".

In addition to designing, effective communication of the design is also essential in design studio education. The second dimension has been generated through identifying the digital tools which are supportive in creative design communication. Students use various methods and mechanisms to explain their design ideation or solutions. In order to do this, the support of digital tools is needed. These digital tools support accurate drafting, sizing, visualizing, prototyping and making explanations and justifications for the developed design (Yavuz \& Yildirim, 2012a). In literature, we identified ten digital tool types that heavily contribute to creative design communication in conventional and non-conventional design studio contexts. Students are using digital tools as an expressive medium to communicate their design to others, especially tutors and other peer learners. In the conventional set-up, design communication is mostly done through pinup panels and paper mock-ups or hybrid mechanisms. However, in non-conventional studio contexts where teaching, learning and collaboration occur through digitally mediated platforms, the appearance of the digital tools for design communication was placed at a higher level. So, we can say the level of dependency on digital design communication tools in NCDS was higher than the CDS found in literature. Since students are engaged within the CDS, in most instances, a hybrid mechanism for design communication with a blend of manual and digital tools is used.

The third dimension, "Digital tools supported for collaboration and mutual learning", explains the types of digital tools used for mutual learning and collaboration in selected literature. According to Pontus, digital tools for collaboration motivate welldefined, device-centric routine engagement (Pontus Wärnestål, 2016). Online collaboration through social media platforms, blogs, virtual workspaces and Web CT are the most commonly used collaborative digital tools. Combining asynchronous tools such as discussion boards; or Moodle was found in literature as digital tools used for collaboration, mutual learning and teaching. (Cho \& Cho, 2014). Güler (2015), in his article, has highlighted what is lacking in the use of digital tools for collaboration; they are face to face dialogues, facial expressions, body language, tone of voice. This is one of the 


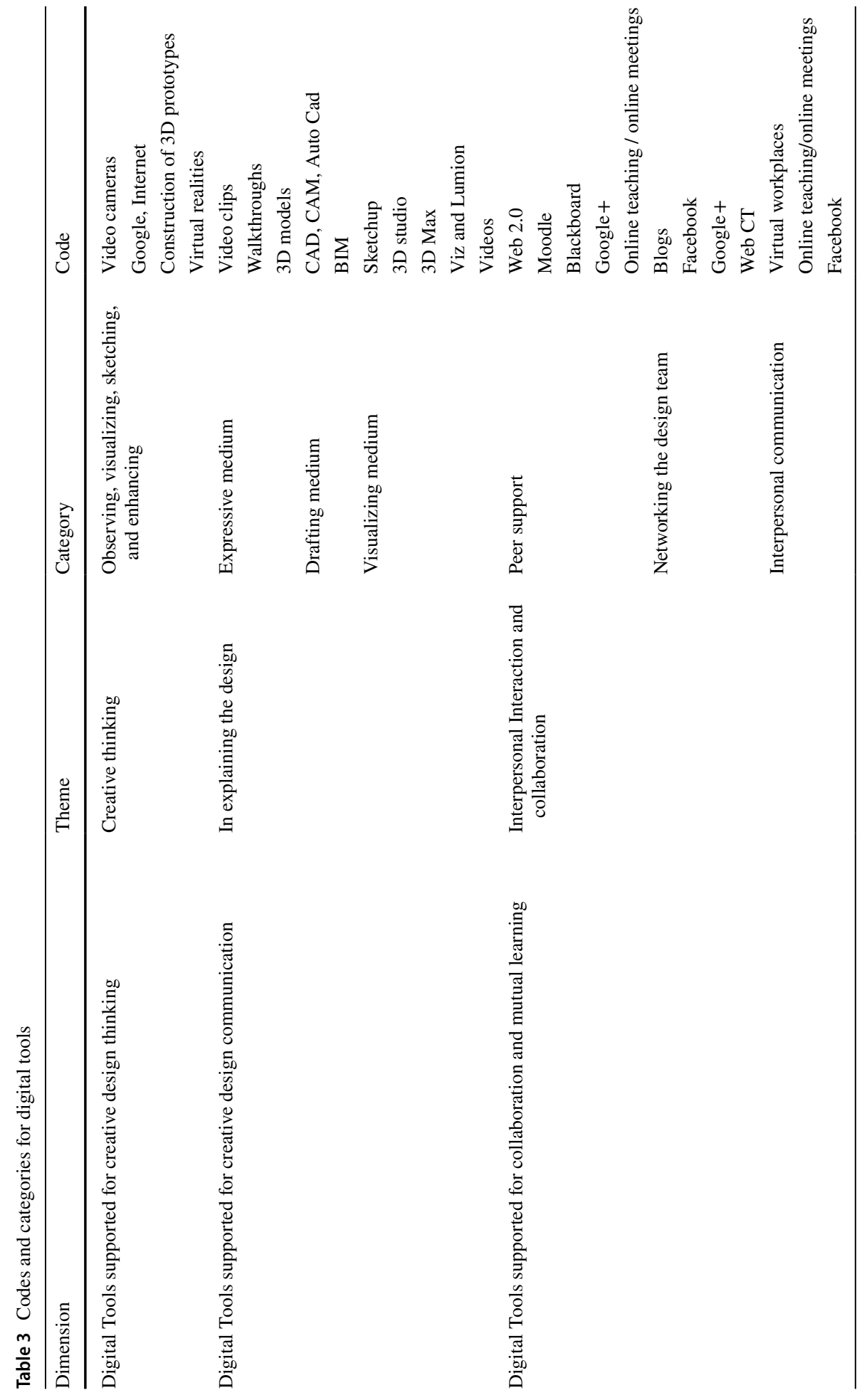


disadvantages identified in digital collaborative tools. However, these digital tools were supportive in collaborating with students beyond the boundaries of the CDS.

We strongly believe that digital tools have escalated design communication skills, design thinking skills, and collaboration and mutual learning among students. However, those tools have some limitations as well. From our point of view, 3D modeling will allow the designer to see and test the design solution in a digitally mediated platform. However, manual prototyping and model making will improve patience and develop students' soft skills. Furthermore, manual tools can replace many digital tools, but the problem is that using manual tools instead of digital tools for design communication, collaboration, and design thinking will consume more time and effort. However, we firmly believe effective amalgamation of both types of tools will be more supportive in carving a good designer, and heavy dependency on one type (digital or manual) will limit the creative potential of the student. Gaining soft skills are indeed essential to be a good designer, and manual tools such as drawing boards, handcrafted paper mock-ups, and panels assist in gaining lifelong skills which are required for designing.

\section{Discussion}

This narrative review aims to understand design studio contexts found in empirical studies, assess the design studio practices that occur in design studios, and identify types of digital tools used in design studios. After reviewing the selected 60 articles, the study identified that the design studio context has not drastically changed from its original form of conventional design studios. In $45 \%$ of the selected articles, it was evident that they were describing the conventional design studio, and $25 \%$ of them were discussing the conventional design studio context in addition to the virtual, blended, online design studios. $56 \%$ of the articles described pedagogical practices and creative design practices in the conventional design studio context. Furthermore, 56\% of the articles were encompassed discussions on pedagogical and creative digital tools used in conventional and virtual design studios.

To answer research question 1: What are the architectural design studio contexts available? The study identified two types of design studio contexts depicted in literature. Conventional design studio contexts and non-conventional design studio contexts are the two main contexts identified. It was evident in literature that CDS and NCDS possess similarities as well as differences. The CDS context could be described as a fixed learning environment with all the physical infrastructure created to support design doings. In contrast, the NCDS utilizes the virtual space, with a heavy dependency on digital tools. CDS is encouraging and depends on heavy paper works and mock-ups. Design students and tutors in the CDS context collaborate face to face. Digital prototyping tools, drawing tools and software, have replaced paper prototyping and heavy paperwork in the NCDS context. However, we noticed that the CDS context had created many limitations. Conventional studio practices could frame the design thinking ability of the students. Moreover, the CDS context has a pedagogical structure that is framed by the context. Limited boundaries of the CDS creates less space for students to explore. Everything occurs within the design studio's four walls, which might limit the students' empathy and sensitivity. The study identified the CDS context as a framed, fixed and stereotypical space that has many limitations.

To answer research question 2: What are the architectural design studio practices available? The study identified pedagogical practices and creative design practices as the key design studio practices depicted in literature. It is difficult to draw a clear margin 
between design studio practices followed in a conventional and non-conventional design studio context. However, we noticed CDS is more focused on bringing the problem into the design studio and solving it collaboratively within the design studio. Problem-based learning is significantly evident in CDSs. The solution-driven mechanism was found in the CDS, and all the studio practices were created to support this mechanism. However, the study identified this problem-based learning as a linear process.

In architectural studies, the end solution and the process followed to generate solutions are equally important. Bringing the problem into the design studio is creating less room to empathize with the real problem. If students are working in real contexts where the problem has been created, they might empathize with the problem more, leading them to generate timeless solutions. This is one of the key problems that were identified in the CDS context. The CDS practice brings experts from the field for students to obtain real-life reflections of the industry. The key role of those expert designers is to influence students and increase their creative thinking by sharing real-life design experiences (Schön, 2016). One drawback of this method is that most students would emulate them, imitate their architectural styles, and design language regardless of the real problem. In the context of the CDS, it was found that due to the lack of exposure experienced by the students, real reflective learning was a challenge, and therefore, needs to be addressed. This is another critical issue identified in CDS practices. In addition to the expert designers, all the other art forms, music, art, theatre, and even life events could influence the design learner via numerous inspirations and stimuli (Charles \& Hokanson, 2009).

Nevertheless, constantly working in a CDS context minimizes the potential of getting exposed, narrowing down their creative thinking parameters. Therefore, it is the view of this study that the design studio practices followed in the CDS context does not lead to an increase in the design thinking ability of students. The studio practices followed has framed the natural design behavior of the students. In NCDS contexts, it was evident that the level of collaboration shows signs of escalation due to the networking ability generated through digital communication tools. However, such digitally mediated platforms played the role of a facilitator, and therefore, did not prove to support the design thinking ability of the students. Further, the research indicated that the virtual design studios and blended studios had also followed the same type of studio practices by working in a virtual context.

To answer research question 3: What are the digital tools and technologies used in architectural design studios? The study identified twenty-six types of digital tools used in design studios. Those digital tools were found to be a supportive medium in all the studio contexts. In the CDS context, the study found that students use digital tools as a supportive medium to improve creative design thinking and as a supportive medium for design communication. It was identified, in NCDS contexts, that the students and teachers engaged via digital tools as a supportive medium for collaboration and mutual learning than utilize the above two functions found in the CDS context. The study identified digital tools as a supportive medium in any design studio context. Those tools cannot replace human creativity and thinking ability which is vital for architectural studies.

Therefore, the study shows how the studio practices followed in CDS have created many limitations, and it has framed the mindset of students, which could limit their creativity. However, more research is required to identify the contextual influences of the design studio to design studio practices. Furthermore, the study shows that a movement from the CDS context is required; however, researchers have not explored this subject over the last ten years. 


\section{Conclusion}

Throughout the last ten years, the research focus has been oriented towards critically examining the design process and practices in design studios, but not in examining the potentials of the context-generated design studios that could be created outside the institutional set-up. It is evident that the research focus of numerous scholars has been pedagogical and creative practices in conventional and virtual/ blended/online design studios. However, the current study is of the view that CDS practices are stereotypical. Furthermore, the current study also revealed that the CDS context has limitations in carving creative designers. It showed that CDS follows conventional design studio practices that were established many decades before, and not much has changed to address the current learning context of the students. These conventional studio practices followed in the CDS context might limit the students' design thinking ability, which needs to be addressed in future research. The fixed space and routine engagement of studio practices have been given less space to explore and feel. Empathizing is a critical phase of the design process, and CDSs have limited room for the students to empathize. Even though the design studio practices consist of field visits, the students strive to resolve those facts within the design studio. This process has limited the thinking and exploring ability of the students. The current study shows that the CDS context provides fewer stimulants to human senses, which are required for design thinking. Students in the CDS context are more solutions-driven; however, the process has received less prominence.

Even in virtual and blended design studios, the exact reflection of the CDS practice was seen. The NCDS contexts gain more support from technology for collaboration, prototyping, and making artifacts. The design process received more prominence in the NCDS context. Therefore, the study proposes that the CDS context requires a transition from its conventional way of practicing and needs to be addressed in future research.

Unorthodox approaches to creating design studios, disregarding the CDS' physical infrastructure and material space, are lacking. Moreover, this review uncovered a gap in the literature pertaining to the potential of transforming the design studio into any other contexts beyond its existing boundaries. The concept of context generated design studios was not addressed in the majority of the selected scholarly articles. The design studio can be where the problem has been generated or where most of the design generators or inspirations are found. On the contrary, it can be any place where students could engage in creative design practices to solve problems through novel designs. The design studio context should not be limited to the institutional set-up. It can be any context, and students and lecturers can create most of the qualitative features of the design studio by engaging in studio practices in their own way. The current study has found a substantial gap in research focusing on context generated design studios, and therefore there is a potential for pursuing future research on context generated design studios.

Funding Open access funding provided by Stockholm University. None.

\section{Declarations}

Conflict of interest The authors declare that they have no conflict of interest.

Open Access This article is licensed under a Creative Commons Attribution 4.0 International License, which permits use, sharing, adaptation, distribution and reproduction in any medium or format, as long 
as you give appropriate credit to the original author(s) and the source, provide a link to the Creative Commons licence, and indicate if changes were made. The images or other third party material in this article are included in the article's Creative Commons licence, unless indicated otherwise in a credit line to the material. If material is not included in the article's Creative Commons licence and your intended use is not permitted by statutory regulation or exceeds the permitted use, you will need to obtain permission directly from the copyright holder. To view a copy of this licence, visit http://creativecommons.org/licenses/by/4.0/.

\section{References}

Adiloglu, F. (2011). Visual communication: Design studio education through working the process. Procedia-Social and Behavioral Sciences, 28, 982-991.

Ardington, A., \& Drury, H. (2017). Design studio discourse in architecture in Australia: The role of formative feedback in assessment. Art, Design \& Communication in Higher Education, 16(2), 157-170.

Baker, J. D. (2016). The purpose, process, and methods of writing a literature review. AORN Journal, 3 , 265.

Bâldea, M., Maier, A., \& Simionescu, O. (2015). Using Blogs as a Communication tool for Teaching Students in the Architecture Design Studio. The Proceedings of 6th World Conference on Educational Sciences, 191, 2758-2762. https://doi.org/10.1016/j.sbspro.2015.04.293

Bashier, F. (2014). Reflections on architectural design education: The return of rationalism in the studio. Frontiers of Architectural Research, 3(4), 424-430.

Brandt, C. B., Cennamo, K., Douglas, S., Vernon, M., McGrath, M., \& Reimer, Y. (2013). A theoretical framework for the studio as a learning environment. International Journal of Technology and Design Education, 23(2), 329. https://doi.org/10.1007/s10798-011-9181-5

Byrne, D. (2016). Data Analysis and Interpretation. Byrne, Research Project Planner. SAGE Publications, Inc. https://doi.org/10.4135/9781526408570

Charles, M., \& Hokanson, B. (2009). The artist and architect: Creativity and innovation through role-based design. Educational Technology, 4, 18.

Chen, W. (2016). Exploring the learning problems and resource usage of undergraduate industrial design students in design studio courses. International Journal of Technology and Design Education, 26(3), 461-487.

Cho, J. Y. (2017). An investigation of design studio performance in relation to creativity, spatial ability, and visual cognitive style. Thinking Skills and Creativity, 23, 67-78. https://doi.org/10.1016/j.tsc.2016.11. 006

Cho, J., \& Cho, M.-H. (2014). Student perceptions and performance in online and offline collaboration in an interior design studio. International Journal of Technology \& Design Education, 24(4), 473-491.

Cho, J., Cho, M.-H., \& Kozinets, N. (2016). Does the medium matter in collaboration? Using visually supported collaboration technology in an interior design studio. International Journal of Technology \& Design Education, 26(4), 567-586.

Ciravoğlu, A. (2014). Notes on architectural education: An experimental approach to design studio. Procedia-Social and Behavioral Sciences, 152, 7-12.

Corazzoa, J. (2019). Materializing the studio. A systematic review of the role of the material space of the studio in art, design and architecture education. Design Journal, 22, 1249-1265. EDSWAH. https:// doi.org/10.1080/14606925.2019.1594953

Corbin, J., \& Strauss, A. (2020). Basics of qualitative research (3rd ed.): Techniques and procedures for developing grounded theory (87-116). SAGE Publications, Inc. https://doi.org/10.4135/9781452230 153

Crowther, P. (2013). Understanding the signature pedagogy of the design studio and the opportunities for its technological enhancement. Journal of Learning Design, 6(3), 18-28.

Djabarouti, J., \& O'Flaherty, C. (2019). Experiential learning with building craft in the architectural design studio: A pilot study exploring its implications for built heritage in the UK. Thinking Skills and Creativity, 32, 102-113.

Durmus Ozturk, S. (2020). Rethinking the black box in architecture design studio. SAGE Open, 10(2). Scopus®. https://doi.org/10.1177/2158244020927408

Edwards, R., \& Miller, K. (2007). Putting the context into learning. Pedagogy, Culture \& Society, 15(3), 263-274. https://doi.org/10.1080/14681360701601887

Emam, M., Taha, D., \& ElSayad, Z. (2019). Collaborative pedagogy in architectural design studio: A case study in applying collaborative design. Alexandria Engineering Journal, 58(1), 163-170. 
Feier, I., \& Milincu, C. O. (2015). Redefining Identity in shopping environments-3rd year interior design studio. Procedia-Social and Behavioral Sciences, 197, 1803-1810.

Fleischmann, K. (2018). Online design education: Searching for a middle ground. Arts and Humanities in Higher Education, 19(1), 36-57. https://doi.org/10.1177/1474022218758231

Fleischmann, K. (2019). From studio practice to online design education: Can we teach design online? Canadian Journal of Learning and Technology, 45(1). https://ezp.sub.su.se/login?url=http://search. ebscohost.com/login.aspx?direct=true \&db=eric\&AN=EJ1214592\&site=eds-live\&scope=site

Fraser, M., \& Don, M. (2011). Thinking through digital simulation tasks in architectural education. Circuit Bending, Breaking and Mending-Proceedings of the 16th International Conference on Computer-Aided Architectural Design Research in Asia, CAADRIA 2011 (pp. 599-608). https://ezp. sub.su.se/login?url=http://search.ebscohost.com/login.aspx?direct=true \&db=edselc \&AN=edselc. 2-52.0-84873499178\&site=eds-live $\&$ scope $=$ site

Gencosmanoglu, A. B. (1), Engin, E. (2), \& Aydintan, E. (2). (2011). First term interior design studio as a process of teaching, learning and expressing. Scientific Research and Essays, 6(16), 3461-3473.

Green, B. N., Johnson, C. D., \& Adams, A. (2006). Writing narrative literature reviews for peer-reviewed journals: Secrets of the trade. Journal of Chiropractic Medicine, 5(3), 101-117.

Grover, R., Emmitt, S., \& Copping, A. (2020). Critical learning for sustainable architecture: Opportunities for design studio pedagogy. Sustainable Cities and Society, 53. edselc. https://doi.org/10. 1016/j.scs.2019.101876

Güler, K. (2015). Social media-based learning in the design studio: A comparative study. Computers \& Education, 87, 192-203.

Ham, J. J., \& Schnabel, M. A. (2011). Web 2.0 virtual design studio: Social networking as facilitator of design education. Architectural Science Review, 54(2), 108-116. EDSWAH. https://doi.org/10. 1080/00038628.2011.582369

Hassanpour, B., Che-Ani, A. I., Usman, I. M. S., Johar, S., \& Tawil, N. M. (2015). Lifelong learning in architectural design studio: The learning contract approach. International Education Studies, 8(1), $1-8$.

Hoskyns, S. (2016). Thematic analysis. In Collected work: Music therapy research. 3rd edn. Rev. Published by: Dallas: Barcelona, 2016. (AN: 2016-21423). Barcelona. https://ezp.sub.su.se/login?url= http://search.ebscohost.com/login.aspx?direct=true \&db=rih\&AN=A1122756\&site=eds-live \& scope $=$ site

Hundhausen, C., Agarwal, P., \& Trevisan, M. (2011). Online vs. face-to-face pedagogical code reviews: An empirical comparison. 6.

Ibrahim, N. L. N., \& Utaberta, N. (2012). Learning in architecture design studio. Procedia-Social and Behavioral Sciences, 60, 30-35.

Ioannou, O. (2018). Opening up design studio education using blended and networked formats. International Journal of Educational Technology in Higher Education, 15(1). https://doi.org/10.1186/ s41239-018-0129-7

Ismail, M. A., Mahmud, R., \& Hassan, I. S. (2012). Digital studio vs. conventional in teaching architectural design process. In 12th International Educational Technology Conference-IETC 2012, 64, 18-25. https://doi.org/10.1016/j.sbspro.2012.11.003

Jennifer, F., \& Muir-Cochrane, E. (2006). Demonstrating rigor using thematic analysis: A hybrid approach of inductive and deductive coding and theme development. International Journal of Qualitative Methods, 5. Directory of Open Access Journals. https://doi.org/10.1177/160940690600500107

Kaiser, K. P., \& Ogoli, D. M. (2016). Expression and evidence, advances in architecture studio pedagogy. Procedia Engineering, 145, 196-202.

Kalantar, N., \& Borhani, A. (2016). Studio in transformation: Transformation in studio. Journal of Architectural Education, 70(1), 107-115. https://doi.org/10.1080/10464883.2016.1122497

Kara, L. (2015). A critical look at the digital technologies in architectural education: When, where, and how? In International educational technology conference, IETC 2014, 3-5 September 2014, Chicago, IL, USA (Vol. 176, pp. 526-530). https://doi.org/10.1016/j.sbspro.2015.01.506

Katherine, C., \& Brandt, C. (2012). The "right kind of telling": Knowledge building in the academic design studio. Educational Technology Research and Development, 60(5), 839.

Kay, B. (2009). Studio based learning: proposing, critiquing, iterating our way to person-centeredness for better classroom management. Theory into Practice, 48(2), 138. https://doi.org/10.1080/00405 840902776459

KhakZand, M., \& Babaei, S. (2018). Developing a new method for the architectural design process: An experimental study using found-object art in the design studio. Design Journal, 21(2), 209-225. https://doi.org/10.1080/14606925.2018.1429368 
Koffeman, A., \& Snoek, M. (2019). Identifying context factors as a source for teacher professional learning. 3, 456. British Library Document Supply Centre Inside Serials \& Conference Proceedings. https://ezp.sub.su.se/login?url=http://search.ebscohost.com/login.aspx?direct $=$ true $\& \mathrm{db}=$ edsbl\&AN=vdc.100082022112.0x000001\&site=eds-live \&scope $=$ site

Kuyrukçu, Z., \& Kuyrukçu, E. Y. (2015). An educational tool the importance of informal studies/studios in architectural design education: A workshop summary. Procedia-Social and Behavioral Sciences, 174, 2666-2673.

Lloyd, P. (2013). Embedded creativity: Teaching design thinking via distance education. International Journal of Technology and Design Education, 23(3), 749. Springer Nature Journals. https://doi.org/ 10.1007/s10798-012-9214-8

Mahmoud, N. E., Kamel, S. M., \& Hamza, T. S. (2020). The relationship between tolerance of ambiguity and creativity in architectural design studio. Creativity Studies, 13(1), 179-198. https://doi.org/10. 3846/cs.2020.9628

Marshalsey, L. (1), \& Sclater, M. (2). (2018). Critical perspectives of technology-enhanced learning in relation to specialist Communication Design studio education within the UK and Australia. Research in Comparative and International Education, 13(1), 92-116. https://doi.org/10.1177/1745499918761706

Marta, M., \& Fuses, J. (2017). Reconceptualizing the design studio in architectural education: distance learning and blended learning as transformation factors. Archnet-IJAR, 2, 6. https://doi.org/10.26687/ archnet-ijar.v11i2.1156

Mewburn, I. (2012). Lost in translation: Reconsidering reflective practice and design studio pedagogy. Arts and Humanities in Higher Education: An International Journal of Theory, Research and Practice, 11(4), 363-379.

Naglaa, M. (2018). Reflections on studio-based learning: Assessment and critique. Journal of Engineering, Design and Technology, 1, 63. https://doi.org/10.1108/JEDT-08-2017-0079

Nicolai, S., \& Khalid, M. S. (2017). The hybrid studio: introducing google+ as a blended learning platform for architectural design studio teaching. Journal of Problem Based Learning in Higher Education, 5(1), 22-46. 1, 22. https://doi.org/10.5278/ojs.jpblhe.v5i1.1562

Orbey, B., \& Sarığlu Erdoğdu, G. P. (2020). Design process re-visited in the first year design studio: Between intuition and reasoning. International Journal of Technology and Design Education, 1. https://doi.org/10.1007/s10798-020-09573-2

Park, S. (2020). Rethinking design studios as an integrative multi-layered collaboration environment. Journal of Urban Design, 25(4), 523-550. https://doi.org/10.1080/13574809.2020.1734449

Park, S., Ryu, J., \& McChesney, K. (2019). Collaborative studio experiences between South Korean and American pre-service teachers: A case study of designing culturally-responsive virtual classroom simulation. TechTrends: Linking Research and Practice to Improve LearningA Publication of the Association for Educational Communications \& Technology, 63(3), 271. Springer Nature Journals. https://doi. org/10.1007/s11528-019-00392-4

Pektas, S. T. (2012). The blended design studio: An appraisal of new delivery modes in design education. Procedia-Social and behavioral sciences, 51, 692-697.

Pektaş, ŞT. (2015). The virtual design studio on the cloud: A blended and distributed approach for technology-mediated design education. Architectural Science Review, 58(3), 255-265. https://doi.org/10. 1080/00038628.2015.1034085

Rodriguez, C., Hudson, R., \& Niblock, C. (2018). Collaborative learning in architectural education: Benefits of combining conventional studio, virtual design studio and live projects. British Journal of Educational Technology, 49(3), 337-353.

Safin, S., Juchmes, R., \& Leclercq, P. (2012). Use of graphical modality in a collaborative design distant setting. In J. Dugdale, C. Masclet, M. A. Grasso, J.-F. Boujut, \& P. Hassanaly (Eds.), From research to practice in the design of cooperative systems: results and open challenges (pp. 245-260). Springer.

SAGE Internet Research Methods. (2019). SAGE Publications Ltd. https://doi.org/10.4135/9781446268513

Saghafi, M. R. (1), Franz, J. (2), \& Crowther, P. (3). (2012). Perceptions of physical versus virtual design studio education. Archnet-IJAR, 6(1), 6-22.

Schon, D. A. (1987). Educating the reflective practitioner. Toward a new design for teaching and learning in the professions. The Jossey-Bass higher education series. Jossey-Bass Publishers. https://ezp.sub. su.se/login?url=http://search.ebscohost.com/login.aspx?direct=true\&db=eric\&AN=ED295518\&site $=$ eds-live \&scope $=$ site

Schön, D. A. (2016). The reflective practitioner: How professionals think in action. Routledge. https://ezp. sub.su.se/login?url=http://search.ebscohost.com/login.aspx?direct=true \&db=edsebk\&AN=1480239\& site $=$ eds-live $\&$ scope $=$ site

Soliman, A. M. (2017). Appropriate teaching and learning strategies for the architectural design process in pedagogic design studios. Frontiers of Architectural Research, 6(2), 204-217. 
Utaberta, N. (1), Ismail, S. (1), \& Othuman Mydin, M. A. (2). (2015). Evaluating joint-studio as a alternative learning experience: Case study of retirement centre project in join-studio between UPM and UIN, in architecture design studio. Jurnal Teknologi, 75(9), 33-38. https://doi.org/10.11113/jt.v75.5225

Utaberta, N., \& Hassanpour, B. (2012). Reconstructing a framework for criteria-based assessment and grading in architecture design studio. Procedia-Social and Behavioral Sciences, 60, 142-149.

Varinlioğlu, G., Pasin, B., \& Clarke, H. D. (2018). Unconventional formulations in architectural curricula: An atelier on design for outer space architecture. A/Z ITU Journal of the Faculty of Architecture, 15(1), 93-105. https://doi.org/10.5505/itujfa.2018.72623

Vosinakis, S., \& Koutsabasis, P. (2013). Interaction design studio learning in virtual worlds. Virtual Reality, 17(1), 59. https://doi.org/10.1007/s10055-013-0221-1

Vyas, D. (2013). Creative practices in the design studio culture: Collaboration and communication, 29.

Wang, T. (2010). A new paradigm for design studio education. International Journal of Art \& Design Education, 29(2), 173-183.

Pontus Wärnestål. (2016). Formal learning sequences and progression in the studio: A framework for digital design education. Journal of Information Technology Education, 1, 35. edsswe. https://doi.org/10. 28945/3406

Wragg, N. (2019). Online communication design education: The importance of the social environment. Studies in Higher Education. https://doi.org/10.1080/03075079.2019.1605501

Yavuz, A. O., \& Yildirim, M. T. (2012a). Study on defining utilization steps of tradiational and digital tools in architectural design education. Procedia-Social and Behavioral Sciences, 51, 239-243.

Yavuz, A. O., \& Yildirim, T. (2012b). Utilization of digital-algorithmic design tools in architectural basic design education. The World Conference on Design, Arts and Education (DAE-2012), May 1-3 2012, Antalya, Turkey, 51, 307-310. https://doi.org/10.1016/j.sbspro.2012.08.164

Yukhymenko, M. A., Brown, S. W., \& Lawless, K. A. (2014). Thematic analysis of teacher instructional practices and student responses in middle school classrooms with problem-based learning environment. 18.

Yurtkuran, S., \& Taneli, Y. (2013). Medium of "Curiosità": An innovative studio environment for design education. Art, Design \& Communication in Higher Education, 12(1), 65-90.

Publisher's Note Springer Nature remains neutral with regard to jurisdictional claims in published maps and institutional affiliations. 